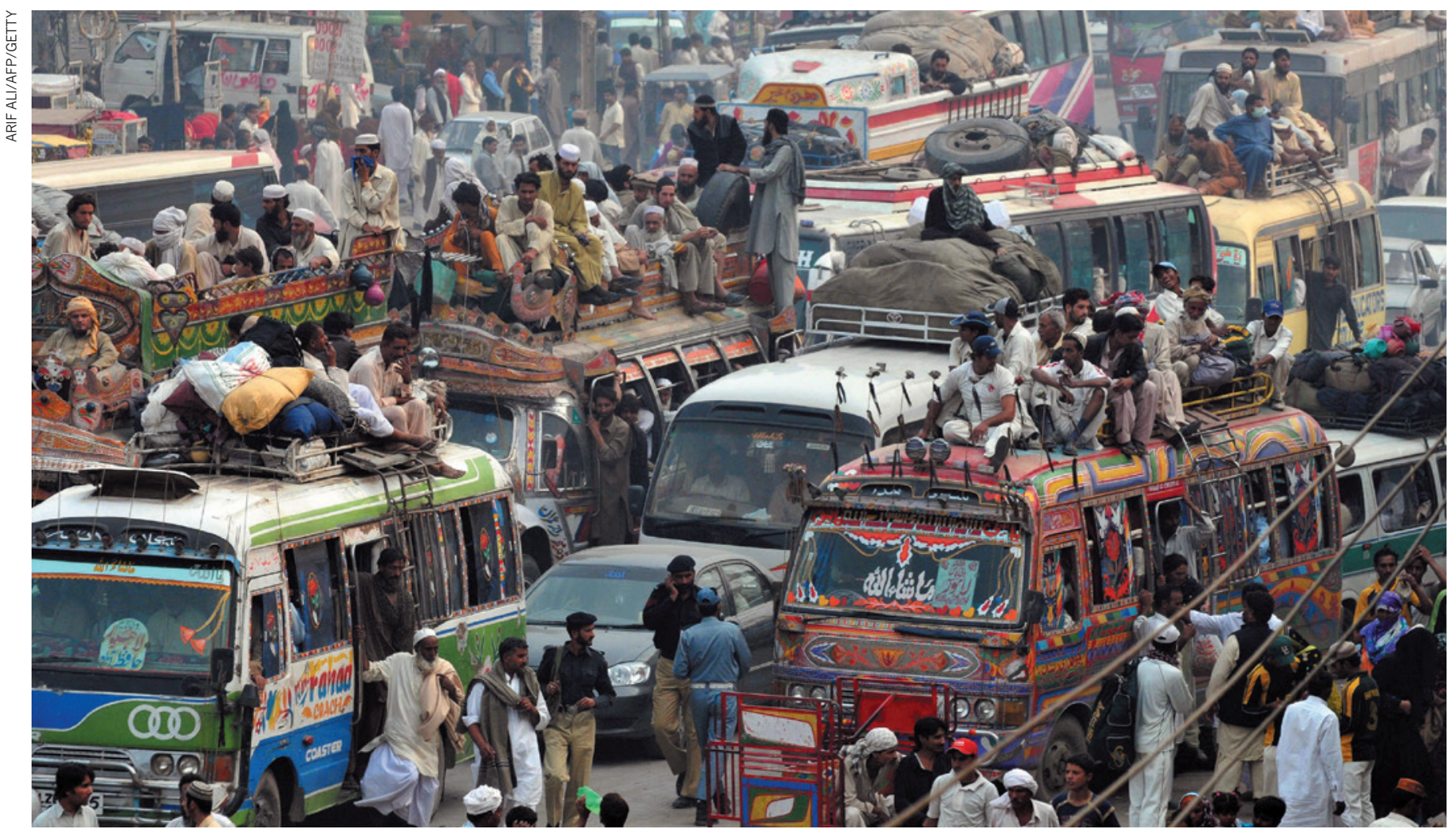

Cities such as Lahore in Pakistan can have traffic jams that last for hours.

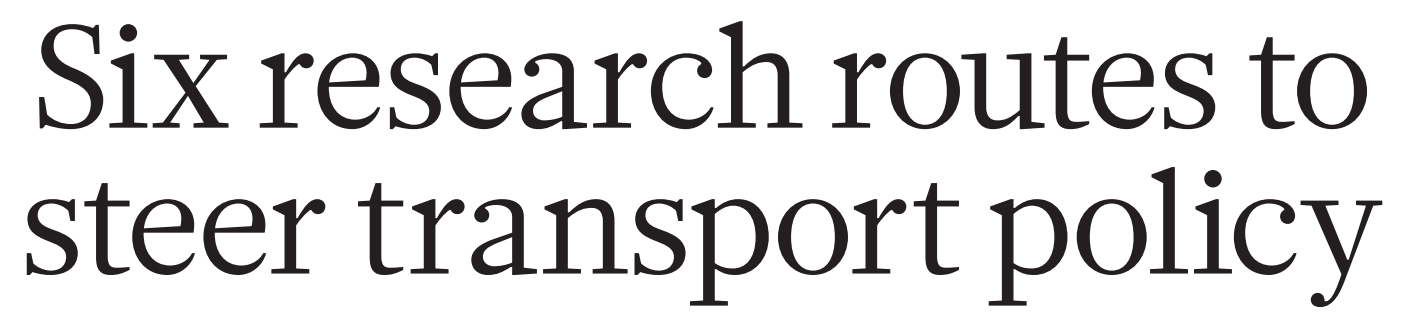

Strategies must better balance the costs and benefits of travel and be realistic about the promises of new technologies, say Eric Bruun and Moshe Givoni.

S ociety is not balancing the benefits and costs of travel. Although technology enables us to get around faster than ever, many cities are gridlocked - São Paulo in Brazil frequently experiences eight-hour traffic jams. More than $90 \%$ of the 1.2 million traffic deaths each year worldwide occur in developing countries and half involve pedestrians, cyclists and motorcyclists. Premature death from vehicle-related fine-particle air pollution worldwide is predicted to rise by $50 \%$ by 2030 . In rich countries, sedentary lifestyles and obesity are in large part the result of our love affair with the car. In poor countries, people may spend two hours walking to work to avoid a modest bus fare.

Transport research is central to twentyfirst-century global challenges that include energy provision, climate change and health. Yet the field is stuck. The language is changing - 'transport' has become 'mobility' and sustainability is more often mentioned in research papers and policy documents. But most planners are still hopelessly trying to fight congestion, and most researchers and policy-makers put too much faith in technological solutions.

Reframing mobility research to answer the following six questions will inform better transport policies.

\section{SIX QUESTIONS}

What are the long-term impacts of new technologies? Although the excitement associated with a new product, service or tool is often justified, the negative, unintended impacts must be anticipated.

Take the driverless car. Depending on whom one asks, such cars will be in wide use in some countries by 2025 or 2050 . They are framed as a technology that offers cheap mobility while saving time and energy ${ }^{1}$. But it was exactly this thinking that brought us the 'with-driver' private car and its unsustainable consequences.

The driverless car promises to be even more successful. Getting people out of their driverless cars will be even harder.

On average, people around the world spend an hour a day travelling, a pattern that has held for centuries and across cultures. When we are able to eat, sleep and work in our driverless cars, this time will become longer, creating a burst of urban sprawl with its associated increases in energy consumption and adverse impacts on the land.

The stakes are too high to believe the promises of new mobility technologies without extensive research that goes beyond the technical, regulatory and commercial. Researchers and policy-makers need to treat any significant technological change as a 'socio-technical' change that alters daily practices and functioning. Protection of personal privacy will be a particular challenge. On the basis of impact assessments, 
governments may need to discourage certain new technologies or encourage their utilization in a particular way. For example, driverless vehicles hold great potential for public transportation.

How should the impacts of transport systems be evaluated? Economic costbenefit analysis is an increasingly controversial method for assessing investment and policy decisions. Transport affects so many aspects of life, particularly in urban areas, over such a long time that a monetary focus alone cannot do the issue justice. Analysis of multiple criteria offers some improvement on cost-benefit, but it is unrealistic to expect to capture all impacts in one score.

Who benefits and who doesn't needs to be accounted for. For example, building motorways through US cities in the 1960s divided low-income black and minority ethnic communities while enabling 'white flight' to the suburbs. Moreover, under the current accounting system, future generations lose out as the discounting of costs and benefits in the future encourages the consumption of non-renewable resources now.

The value placed on travel time needs to be reconsidered. It can be a waste and viewed as a monetary cost, but with wireless technology or a good book it can also be productive and fun - even more so when the driverless car arrives.

Travel behaviour models - used to project future demand - are crucial for any evaluation. Increasingly sophisticated models that are largely based on random utility theory from mathematical psychology have been developed over the past 30 years to better capture reality. But they are so complex and expensive that most cities cannot afford them or collect the data required. Results that can be comprehended only by the modellers are not transparent enough to support democratic decision-making.

Researchers must come up with new

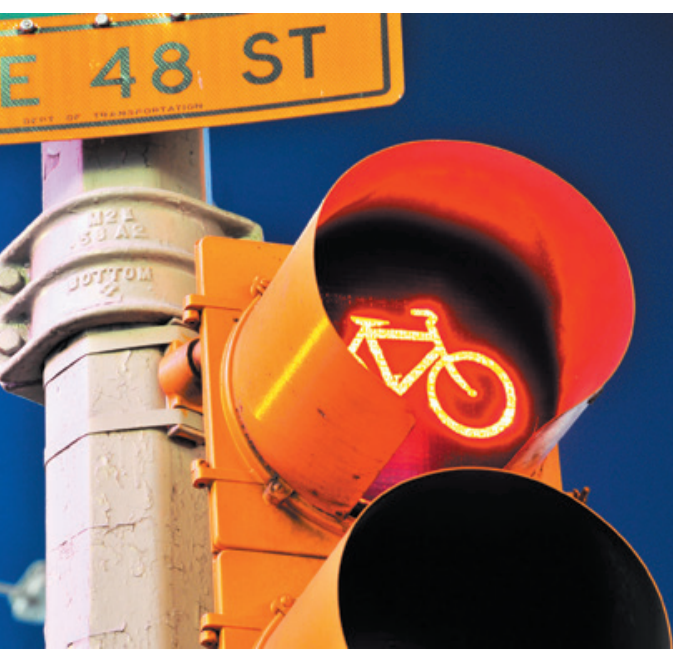

New York City is introducing more bike lanes. evaluation methods that are robust and scientifically defensible. The outputs must be comprehensible to elected officials and to the public. Such methods must include both quantitative and qualitative benefits and costs, and capture a much larger array of them. For example, researchers might consider whether the public perceives that the comfort and beauty of their city will improve or deteriorate after a major investment.

A good example is the Øresund EcoMobility project, a joint effort between Swedish and Danish

city and regional governments and universities to rethink transport in cities around the Øresund strait, including Copenhagen and Malmö. It is combining "The majority of research money for transport currently goes to technological development with commercial potential."

cost-benefit analysis with risk assessment and qualitative impacts of interest to the population, determined at a 'decision conference' at which planners and public representatives can see and hear differences of opinion.

How does the structure of cities affect sustainability, living standards and functioning costs? Studies of urban density, energy consumption and travel statistics show that altering the form of cities to reduce greenhouse-gas emissions is as effective as improving technologies and substituting fuels, yet it receives much less attention ${ }^{2}$. Energy consumption per capita by private vehicles declines with higher urban density, for instance (see 'Transport trends') ${ }^{3}$.

Total expenditures (public and private) on passenger transport decrease as urban density increases. Yet zoning and infrastructure investment decisions are not based on broader scientific analyses of the impacts. Understanding the drivers of sprawl is of vital importance for fast-growing cities such as Mexico City, Delhi or Lahore in Pakistan that are swallowing up adjacent farmland and wetlands.

Researchers need to consider more fully urban transport alongside other features of the built environment. We know, for example, that taller buildings and smaller areas used per person for a given type of activity (residential, commercial or recreational) tend to be associated with compact and energy-efficient cities, such as Hong Kong. Yet planners lack accurate models for land use development that consider many design variables.

Scientists and planners urgently need to understand the significance of changes in urban development plans on the construction and operating costs of all aspects of the built environment, on total urban energy consumption, on living standards and on space consumption. To accomplish this, universities and urban governments need to break down traditional borders between disciplines and professional responsibilities.

How can mobility beyond cities be improved? Transport links beyond cities are important for regional development. The exodus of people from the countryside to cities in search of employment is intensifying urbanization worldwide and increasing pressure on scarce resources. Urbanization scholars highlight the rapid growth of megacities, but smaller cities and villages must also be considered.

Researchers need to model how better connections - local, regional and between a city and its hinterlands - might improve the prospects of smaller towns and rural areas. Studies need to be more inclusive, politically neutral and regionally equitable. Transport investments often favour large cities and their links with expensive, fast transport options. The opportunity costs - what a government could have done with the money - are not considered sufficiently.

For example, the UK government plans to spend more than $£ 40$ billion (US $\$ 63$ billion) on High Speed 2, a 400-kilometre-per-hour rail link between London and Birmingham and (later) Manchester. In our view, the money would be better spent on improving the country's entire public-transport network, which is poor by European standards, and on local and regional transport, which is currently dominated by private-car use $\mathrm{e}^{4}$. Joining up many small cities could benefit the national economy and society: for every 12 jobs created in cities in the south of England between 2004 and 2013, only one was created elsewhere in Britain. Many other countries and regions face similar decisions.

How could transport be improved in developing countries? Researchers need to assess and suggest ways to establish rapid, cheap and effective transport systems in poor nations. Elaborate physical redesigns of infrastructure, similar to those made by high-income countries, take too much time and money to implement. Instead, developing countries should learn from developed countries' planning mistakes. They could also 'leapfrog' to the latest technologies.

For example, in Nairobi in 2013, student bus passengers were issued with smartphones that allowed city planners and researchers to track their routes, count riders and identify areas of congestion (see go.nature. com/ihhy6t). An app that contacts a traffic signal to let a bus through an intersection can aid mobility flow. Private-sector investment in such systems is low because of the lack of commercial prospects for what seems like simple technology. Public-sector funding of such applied research and collaborations between universities from high- and 


\section{TRANSPORT TRENDS}

Sprawling metropolises such as Atlanta, Georgia, have higher energy consumption per capita because their residents are highly dependent on cars for long journeys, whereas cities such as London and Hong Kong have higher building densities and more public transport.

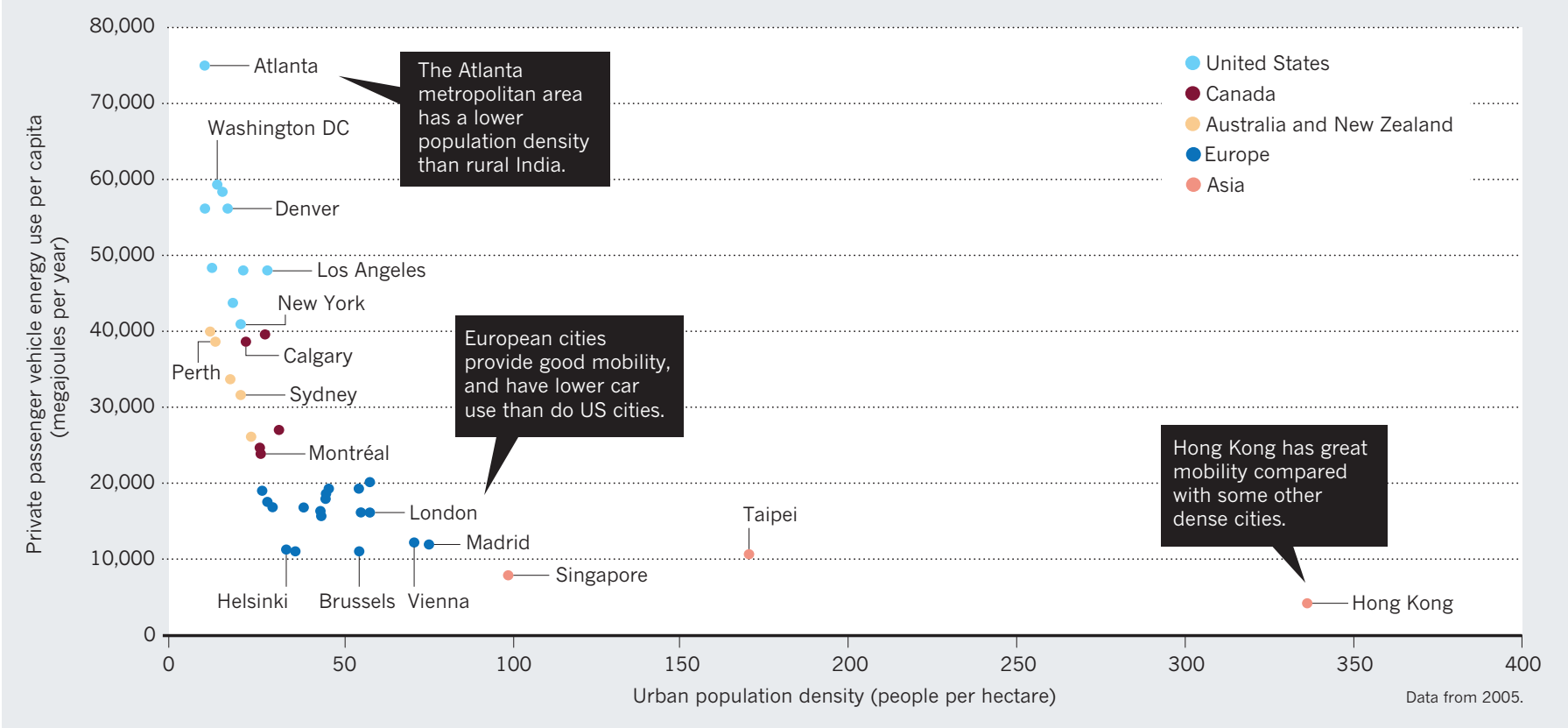

low-income countries should be encouraged.

But technology can get in the way. For example, farmers in South Asia experience impassable roads during the rainy or monsoon season. Money would be better spent on gravelling or paving farm tracks than on widening major roads linking large cities. Similarly, investing in standard bus services that have been allowed to wither, rather than in more sophisticated high-capacity rail and bus mass-transit systems that mimic those in developed countries, will be more beneficial. It will be cheaper, realized sooner, carries lower risk, and importantly the benefits will be wider spread across the city and its inhabitants.

What kinds of governance work for the transport system? Services such as Uber - the taxi smartphone app that connects passengers with drivers in dozens of cities worldwide - and variants of car sharing have caught the transport planning sector by surprise; institutions are not sure whether to support or fight these advances. Like any innovation they are a great opportunity but also carry risks. Even with shared cars, it is physically impossible for large cities to meet everyone's travel needs with what is essentially a variation of single-occupant vehicles. When finding that parking a car is not an issue any more, people may flock again to cars, reversing the accessibility, sustainability and livability trends experienced in many cities such as New York, which is promoting public transport, cycling and walking as modes of transit. So, good public transit will be needed more than ever to compete with the car.
Research is needed to understand the policy implications of rapid changes in transport technologies and systems and how institutions should evolve to accommodate them ${ }^{5}$. Methodologies and tools are needed for devising effective policies, combining them strategically and overcoming implementation barriers such as public and political acceptability.

One methodology that could be expanded is 'policy packaging', in which a combination of instruments is implemented while steps are taken to minimize unintended effects and increase the chances of an intervention's success. For example, London's congestioncharge scheme - which charges car users a fee to enter the city centre during certain hours - was accompanied by improvements to public transport and heavy discounts for residents within the zone ${ }^{7}$. Such policy packages have been suggested for promoting carsharing services in European cities (see, for example, www.spreeproject.com).

\section{FRESH THINKING}

Governments should support system-level research that is needed by the public sector yet attracts scant funding from the private sector. The majority of research money for transport currently goes to technological development with commercial potential such as the driverless car - which already receives private funding.

Universities and governments need to realign research incentives to support the interdisciplinary scholarship needed. This includes stable funding and centres that can attract and nurture a variety of talent and cross-border collaboration, especially where there is lack of commercial potential but great promise to society. If not, researchers will remain in narrow specialities in which funding and publishing are safer.

Our transport systems, as well as our cities, must be planned for people - not for a particular mode of transport or by a handful of companies with vast lobbying power. Delivering low-carbon mobility for all will take fresh thinking ${ }^{8}$.

Eric Bruun is a visiting professor in the Department of Civil and Environmental Engineering, Aalto University, Espoo, Finland. Moshe Givoni is head of the Transport Research Unit, Department of Geography and the Human Environment, Tel Aviv University, Tel Aviv, Israel. e-mails:eric.bruun@gmx.com; givonim@post.tau.ac.il

1. Burns, L. D. Nature 497, 181-182 (2013).

2. Bruun, E. C. Characterizing and Influencing Modal Relationships, Better Public Transit Systems: Analyzing Investments and Performance 2nd edn Ch. 5 (Routledge, 2014).

3. Newman, P. \& Kenworthy, J. The End of Automobile Dependence: How Cities are Moving Beyond Car-Based Planning (Island Press, 2015).

4. Givoni, M. \& Banister, D. J. Transp. Geogr. 22, 306-307 (2012).

5. Schiller, P. L., Bruun, E. C. \& Kenworthy, J. R. An Introduction to Sustainable Transportation: Policy Planning and Implementation Ch. 8 (Earthscan/ Routledge, 2010)

6. Givoni M., Macmillen, J., Banister D. \& Feitelson, E. Transp. Rev. 33, 1-20 (2013)

7. Givoni, M. Urban Studies 49, 1089-1105 (2012).

8. Banister, D., Givoni, M., Macmillen, J. \& Schwanen, T. in Moving Towards Low Carbon Mobility (eds Givoni, M. \& Banister, D.) (EdwardElgar, 2013). 